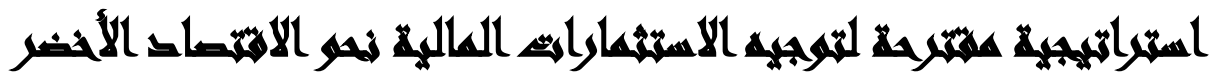

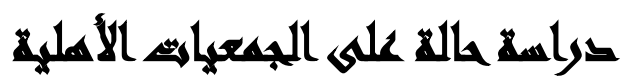

\section{[1 $\leqslant]$}

\author{
محمود محمد صبح'(')- مصطفى إبراهيم عوض(ץ) - وائل فوزي عبدالباسط(')

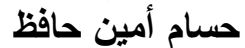

() كلية التجارة، جامعة عين شمس r) معهد الدراسات والبحوث البيئية، جامعة عين شمس حس

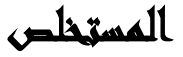

تهدف الدراسة إلى التوجه نحو الاقتصاد الأخضر وكذلك دور الجمعيات الأهلية في

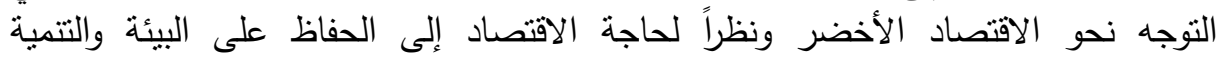

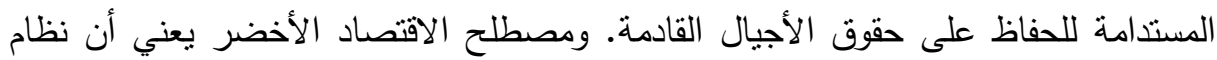

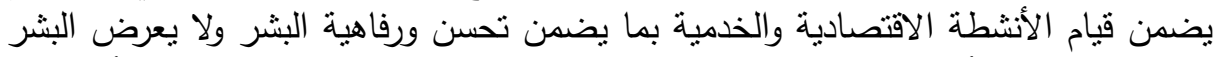

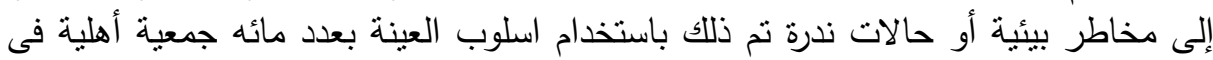

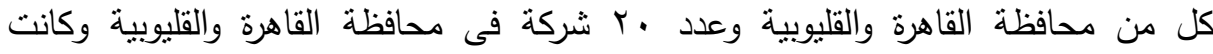

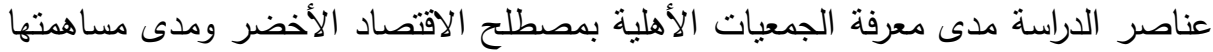

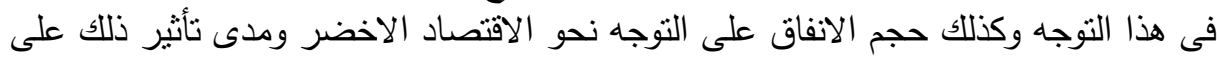

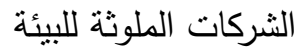

وقد خلصت الدراسة إلى قلة عدد الجمعيات التي تعمل في التوجه نحو الاقتصاد

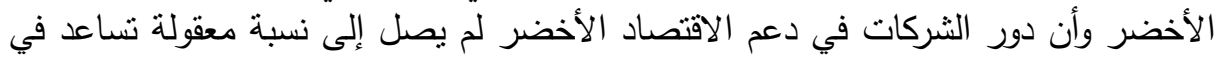

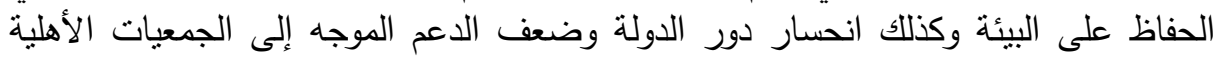

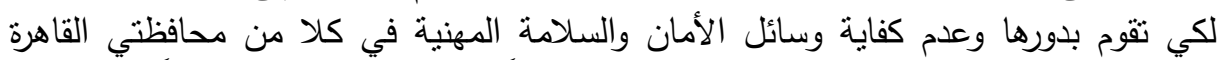

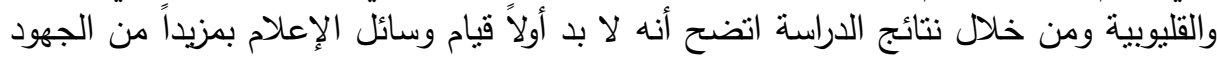
للتعريف وأهمية التوجه نحو الاقتصاد الأخضر، وكذلك قيام الدولة بدانة التهم الجمعيات الأهلية

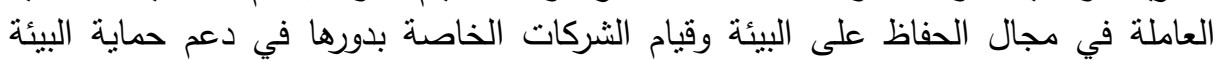

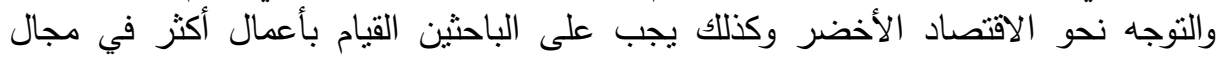
التوجه نحو الاقتصاد الأخضر . الأنص 


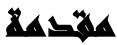

جاء مصطلح الاقتصاد الأخضر من الربط بين الاقتصاد والبيئة ويعرف الاقتصاد

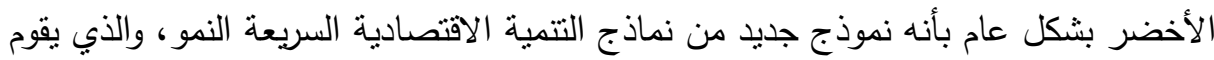
أساسه علي المعرفة للاقتصاديات البيئية والتي تهدف إلي معالجة العلاقة المنبادلة ما بين الاقتصاديات الإنسانية والنظام البيئي الطبيعي والأثر العكسي للنشاطات الإنسانية علي التغير المناخي والاحتباس الحراري وهو يناقض نموذج ما يعرف بالاقتصاد الأسود والذي علي أساسه يقوم علي استخدام الوقود الأحفوري مثل الفحم الحجري والبتزول والغاز الطبيعي وقد يبدو

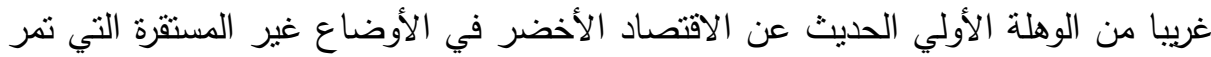

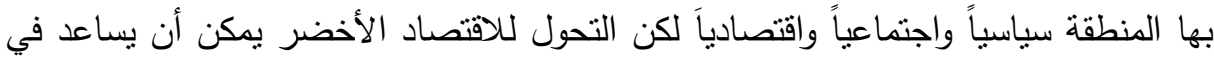

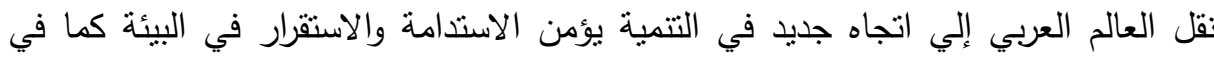
الاقتصاد حيث تتمحور المبادئ الأساسية للاقتصاد الأخضر حول إعطاء وزن متساو للتتمية الاقتصادية والعدالة الاجتماعية والاستدامة البيئية وتلبية هذه الأهداف الثلاثة توفر أساساً سليماً لمعالجة نقاط الضعف في الاقتصاديات العربية من تحقيق الفقر والبطالة إلي تحقيق أمن غذائي إلي توزيع أكثر عدالة للاخل مما يحقق استقرارا مجتمعياً وأمنياً.(أبوطير نبيل الهيل

( ) $(r \cdot) \cdot-r \cdot q$

وقد ظهر دفهوم الاقتصاد الأخضر استجابة لهذه الأزمات المتعددة وهو يسعي إلي تحويل المحركات الدافعة للنمو الاقتصادي ويدعو إلي نقل المجالات التي تركز عليها الاستثمارات العامة والخاصة والمحلية والدولية صوب القطاعات الخضراء الناشئة وإلي تركي خضرته القطاعات القائمة وتغيير أنماط الاستهلاك غير المستدامة وينتظر أن يولا هذا التحول النمو الاقتصادي المستمر اللازم لإيجاد فرص العمل والحد من الفقر إلي جانب نقليل كثافة استخدام الطاقة واستهلاك الموارد وإنتاجها. ويعرف برنامج الأمم المتحدة للبيئة "الاقتصاد الأخضر" بأنه نظام أنشطة اقتصادية

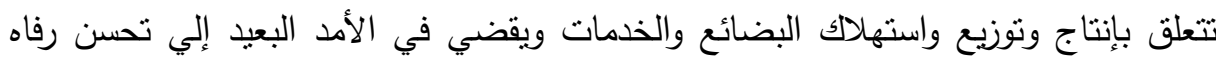
البشر ولا يعرض في الوقت نفسه الأجيال المقبلة إلي مخاطر بيئية أو حالات ندرة ولثات 
ويتبني الاقتصاد الأخضر الطاقة الخضراء التي يتم نوليدها بواسطة الطاقة المتجدة

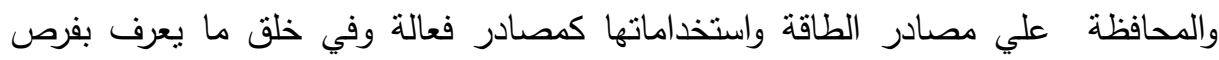
العمل الخضراء والإنتاج الأخضر الذي يشمل الزراعة العضوية وتتجع المنتجات العضوية والمتاجر الخضراء. بالإضافة إلي ضمانة النمو الاقتصادي المستدام والحقبقي ومنع التلوث البيئي والاحتباس الحراري واستنزاف الموارد الطبيعية. لقد احتل مفهوم المنظمات غير الحكومية ذيوعا وانتشاراً كبيراً في الخطاب العربي المعاصر وأصبح من المفاهيم الثنائعة والمألوفة ومن ثم المقبولة رغم ما أثناره هذا المفهوم من فئل

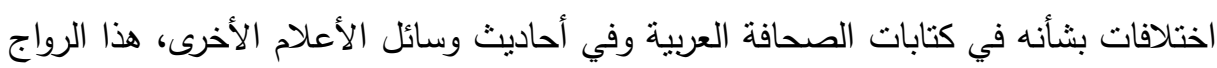
الهائل لمفهوم المنظمات غير الحكومية ازداد رسوخاً وانتتاراً في ظل المتغيرات العالمبة والتي

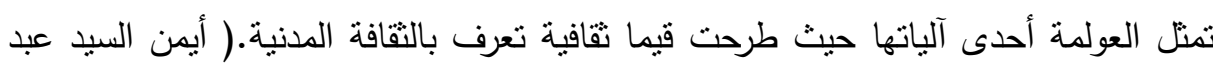

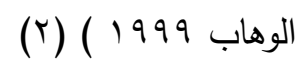
كما ساهمت في تأسيس شبكات عالمية وإقليمية بطلق عليها المنظمات غير الحكومية عبر القومية وكذلك عولمة قوانين المنظمات غير الحكومية فضلا عن مواثيق الثرف الأخلاقية فيما يعرف بأخلاقيات المنظمات غير الحكومية.

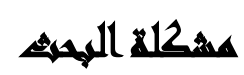

مشكلة البحث تتلخص فى عدم التوجه نحو الاقتصاد الأخضر الذى يضمن خفض معدلات التلوث والحفاظ على البيئة لتحقيق التتمية المستدامة. وتعانى جمهورية مصر العربية مثلها كبقية الدول فى العالم من آثار التلوث ونظراً لأهمية الموضوع محل البحث. ولقد قام الباحثون بإجراء دراسة استطلاعية بتطبيق استبيان للتعرف على دور الجمعيات

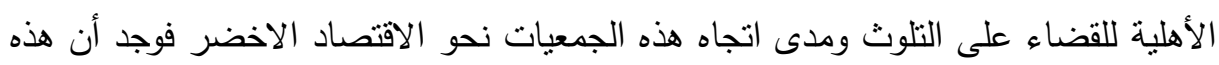
المشكلة لم تأخذ الاهنمام الكافى من قبل المنظه التهات. 
ومن ثم قام الباحثون بدراسة الحالة نحو التوجه إلى الاقتصاد الاخضر من خلال دور

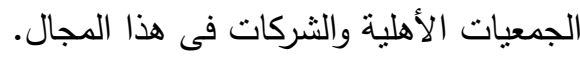

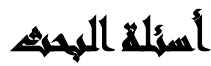

• ما مدى قيام الجمعيات الأهلية تقوم بدور فعال نحو الاتجاه للاقتصاد الاخضر؟

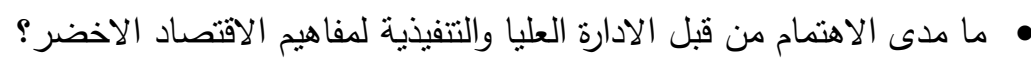

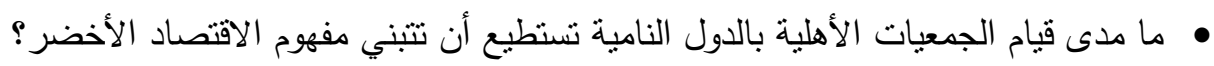

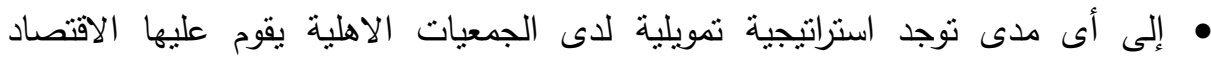

الأخضر؟

• كيف يمكن تفعيل دور الجمعيات الأهلية في إيجاد مجالات جديدة تصلح لنمو الاقتصاد

الأخضر؟

• ما هو دور المنظمات الأهلية في تغيير أنماط الاستهلاك وكذلك ترشيد الموارد بما يتتاسب

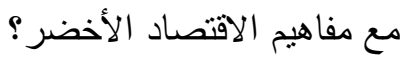

\section{أهسا هـث المهنه}

• وضع استراتيجية مقترحة للجمعيات الأهلية في توجيه الاستثمارات نحو الاقتصاد

الأخضر - آن

• وضع آليات لتتفيذ الاستراتيجية للتحول إلي الاقتصاد الأخضر •

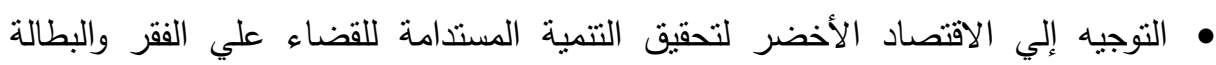

$$
\text { وتعزيز قاعدة الموارد الطبيعية. }
$$

• تفعيل دور المنظمات الأهلية في توجيه المجتمع نحو الاقتصاد الأخضر .

• دراسة المعوقات التي نواجه المنظمات الأهلية للقيام بعملها نحو التوعية البيئية. 


\section{هروض الهمبش}

ا. هناك علاقة ذات دلالة إحصائية بين دور الجمعيات الأهلية في التحول نحو الاقتصاد

$$
\text { الأخضر والموارد المالية لهذه الجمعيات. }
$$

r. هناك علاقة ذات دلالة إحصائية بين وجود استراتيجية لدور الجمعيات الأهلية نحو التوجه

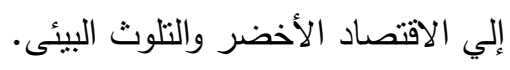

r. هناك علاقة ذات دلالة إحصائية بين وجود استراتيجية للجمعيات الأهلية وخلق فرص الاتئ عمل جديدة. ع. هناك علاقة ذات دلالة إحصائية بين المعوقات المادية ودور الجمعيات في التوجه نحو

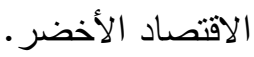

\section{مصوض القواسما}

محافظة القاهرة ومحافظة القليوبية بعدد . .1 جمعية لكل محافظة و •r شركة لكل

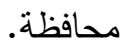

\section{المسطلحاهي}

• الاقتصاد الأخضر ( يقصد به استخدام الطاقة النظيفة فى الثركات )

• الجمعيات الاهلية ( هى منظمات أهلية نساعد المجتمع فى حل بعض مشكلاته )

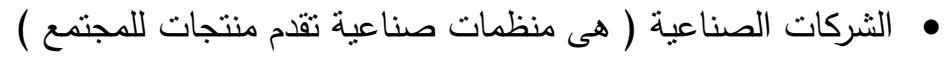

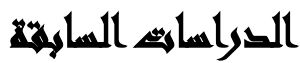

* قامت د/ حنان محمد سليمان ـ ـ ب دور الجمعيات الأهلية في حماية البيئة. تتاولت الرسالة دراسة وصفية مطبقة علي مدينة الإسكندرية لرصد الدور الذي تقوم به

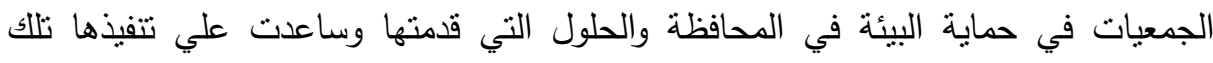

$$
\text { الجمعيات للقضاء علي التلوث البيئي. }
$$

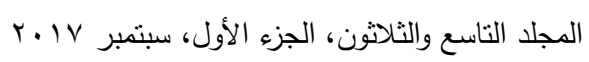


وأكدت الدراسة علي أهمية دور الجمعيات الأهلية في نوعية المواطنين بأهمية مواجهة

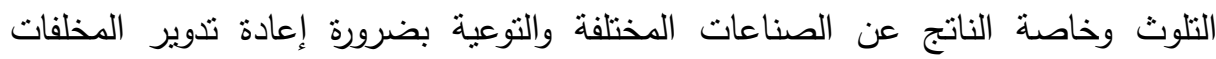

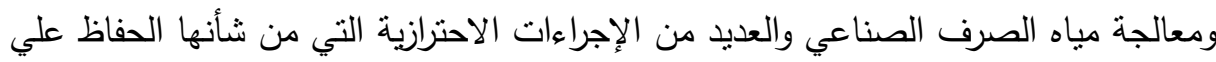

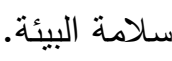

\section{قام برنامج الأمم المتحدة للبيئة نحو اقتصاد أخضر 11 ـ ب القضايا الناثئة في} مجال السياسة العامة البيئة والتتمية للاقتصاد الأخضر . ويهدف المؤتمر إلي استعراض أحدث ما استجد علي المستويين الدولي والوطني من تطورات تتعلق بالاقتصاد الأخضر ودراسة العلاقة بين الاقتصاد الأخضر وأولويات وطنية رئيسية منل التجارة والعمالة والقضاء علي الفقر . وتوصل المؤتمر إلي أنه يجب اتخاذ تدابير مناسبة علي صعيد السياسات لإتاحة

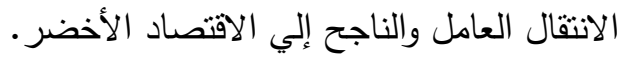
كذلك يجب إنشاء أطر قابلية وسليمة لتشجيع الأنشطة الاقتصادية الخضراء وإزالة

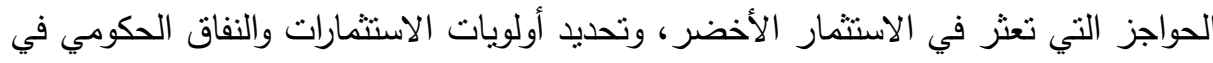
المجالات التي تستتفذ رأس المال الطبيعي. قام ديرك مينز || | ب بدراسة حول نحو اقتصاد أقل اعتماد علي الكربون تهدف الدراسة إلي تعزيز الجهود الدولية الرامية إلي خفض انبعاثات الكربون ينبغي أن نركز علي دعم

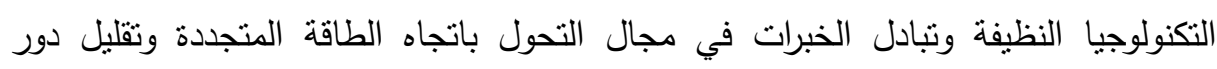

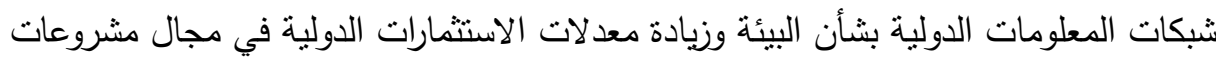

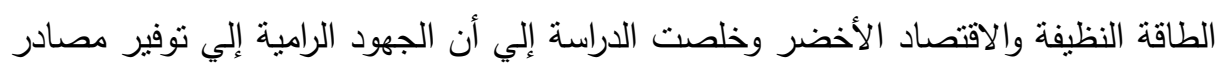
الطاقة الأمنة والنظيفة تهدف إلي الحد من الطلب العالمي علي الطاقة الكربونية وضمان توفير خدمات تكنولوجيات جديدة أقل اعتمادا علي الطاقة الكربونية في مختلف القطاعات ومن أهمها النقل والتشييد والبناء والصناعة. 
قامت دراسة (شهيدة الباز): بدراسة حول المنظمات الأهلية العربية على مشارف القرن

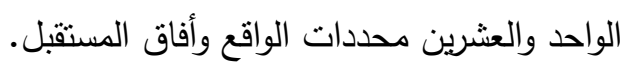

في دراستها ترى الباحثة أن التتمية الثشاملة المعتمدة على البشر مازلئن الت تمثل التحدي

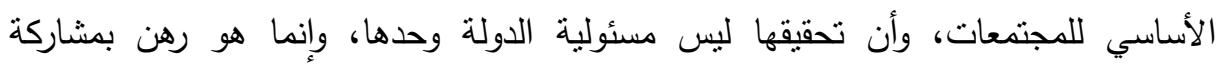

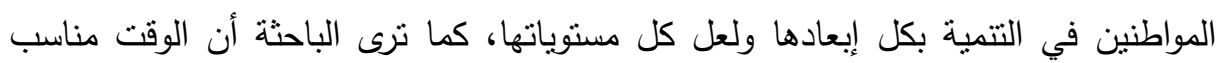

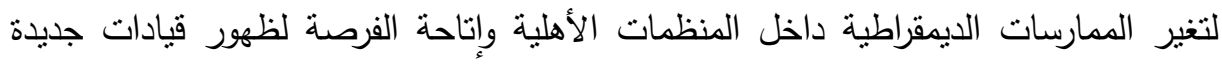
وكنلك تشجيع المشاركة النسائية في المنظمات غير الحكومية، وفي النهاية توصى الباحثة بأهمية تشجيع الدراسات والبحوث الخاصة بالقطاع الأهلي مع التركيز على الاحتياجات

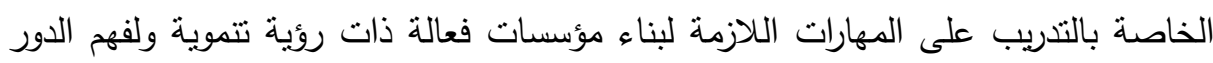
الجديد لهذا القطاع. قامت دراسة (نجوى عبد الله): القطاع الأهلي والتنمية الاقتصادية في مصر: نتاولت

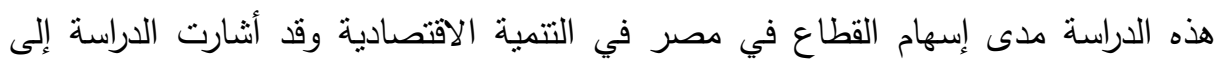
المراحل التاريخية التي مرت بها الجمعيات وهي: • مرحلة الإغاثة. • مرحلة التتمية. • • مرحلة التتمية المستدامة وهي المرحلة الحالية لعمل الجمعيات. وقد نوصلت الدراسة إلى أنه لكي تستطيع المنظمات غير الحكومية أن تحسن من نوعية

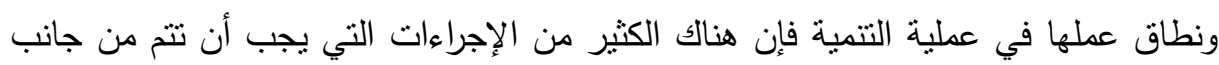
جهات مختلفة على مستويات مختلفة وتتمثل في المنظمات غير الحكومية نفسها - القطاع الحكومي - اللجان والمنظمات للمساعدات والهيئات.

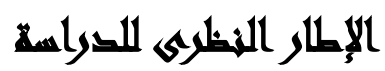

جاء مصطلح الاقتصاد الأخضر من الربط بين الاقتصاد والبيئة ويعرف الاقتصاد

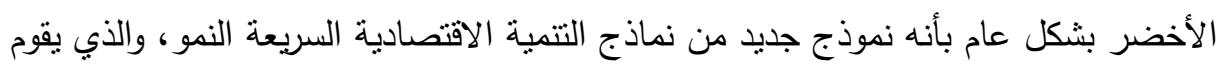

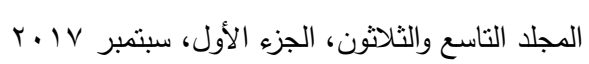


أساسه علي المعرفة للاقتصاديات البيئية والتي تهدف إلي معالجة العلاقة المتبادلة ما بين

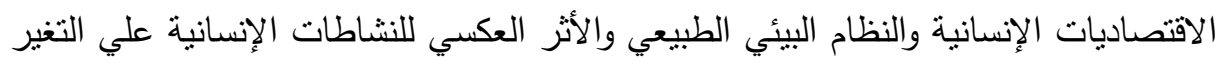

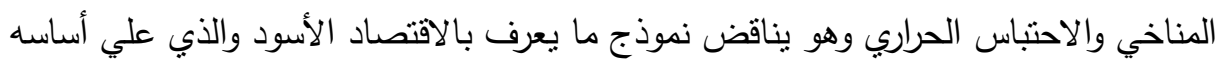

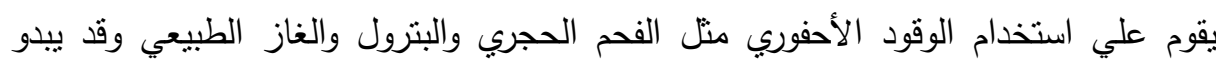

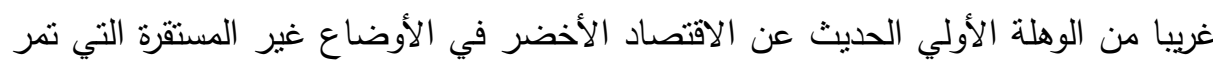

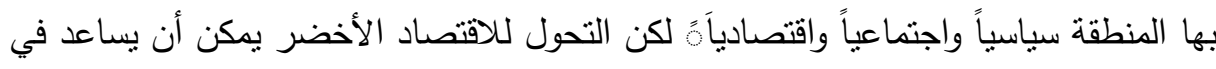

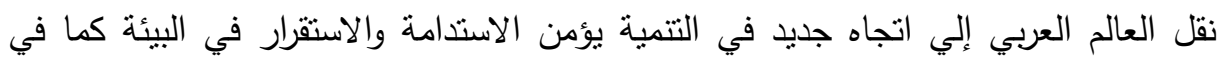
الاقتصاد حيث تتمحور المبادئ الأساسية للاقتصاد الأخضر حول إعطاء وزن منساو للتنمية الاقتصادية والعدالة الاجتماعية والاستدامة البيئية وتلبية هذه الأهداف الثلاثة توفر أساساً

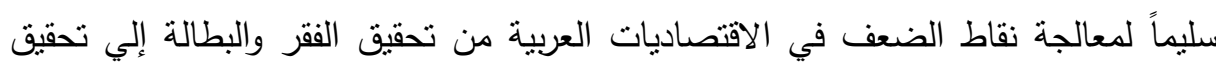
أمن غذائي إلي نوزيع أكثر عدالة للاخل مما يحقق استقرارا مجتمعياً وأمنياً.

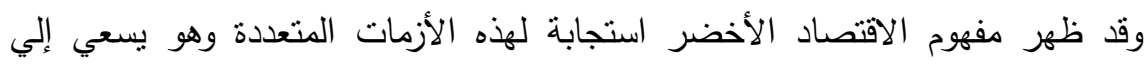
تحويل المحركات الدافعة للنمو الاقتصادي ويدعو إلي نقل المجالات التي تركز عليها الاستثمارات العامة والخاصة والمحلية والدولية صوب القطاعات الخضراء الناشئة وإلي خضرته القطاعات القائمة وتغيير أنماط الاستهلاك غير المستدامة وينتظر أن يولا هذا ولهاب التحول النمو الاقتصادي المستمر اللازم لإيجاد فرص العمل والحد من الفقر إلي جانب تقليل كثافة استخدام الطاقة واستهلاك الموارد وإنتاجها. ويعرف برنامج الأمم المتحدة للبيئة "الاقتصاد الأخضر " بأنه نظام أنشطة اقتصادية التهادية تتعلق بإنتاج وتوزيع واستهلاك البضائع والخدمات ويقضي في الأمد البعيد إلي تحسن الأنس رفاه

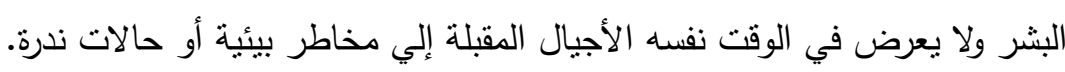

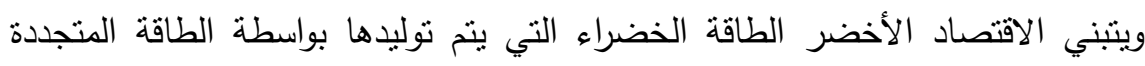

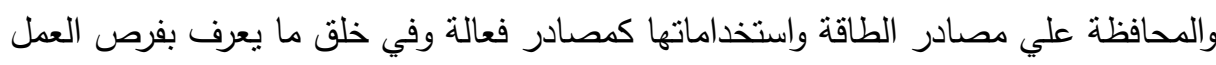
الخضراء والإتتاج الأخضر الذي يشمل الزراعة العضوية وتتجع المنتجات العضوية والمتاجر 
بالإضافة إلي ضمانة النمو الاقتصادي المستدام والحقيقي ومنع التلوث البئي والاحتباس الحراري واستتزاف الموارد الطبيعية.

لقد احتل مفهوم المنظمات غبر الحكومية ذيوعا وانتشاراً كبيراً في الخطاب العربي المعاصر وأصبح من المفاهيم الثنائعة والمألوفة ومن ثم المقبولة رغم ما أثناره هذا المفهوم من اختلافات بشأنه في كتابات الصحافة العربية وفي أحاديث وسائل الأعلام الأخرى، هذا الرواج الهائل لمفهوم المنظمات غير الحكومية ازداد رسوخاً وانتتاراً في ظل المتغيرات العالمية والتي تمثل العولمة أحدى آلياتها حيث طرحت قيما ثقافية تعرف بالثقافة المدنية. كما ساهمت في تأسيس شبكات عالمية وإقليمية بطلق عليها المنظمات غير الحكومية باتية عبر القومية وكذلك عولمة قوانين المنظمات غير الحكومية فضلا عن مواثيق الثرف الأخلاقية فيما يعرف بأخلاقيات المنظمات غير الحكومية. لذا شهدت العقود القليلة الماضية اهتماما عالميا ومحليا بدور المجتمع المدني في قضايا حماية البيئة ونشر الوعي البيئي وحماية حقوق الإنسان وتشر ثقافة العمل التطوعي خاصة

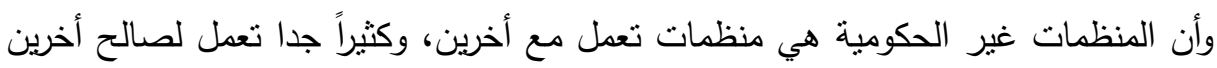

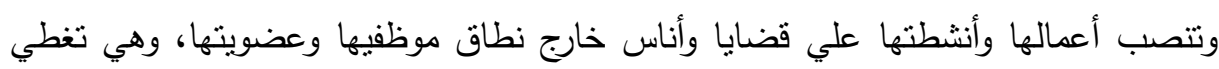
مجالاً واسعاً للغاية يبدأ من المنظمات المحلية مرورا إلي الاتحادات الوطنية والثبكات الدولية. ولعل سعي المنظمات غير الحكومية في حماية البيئة من النلوث ونشر الوعي البيئي من أهم الجهود التي تبذلها هذه المنظمات في هذا الثنأن فمنذ مؤتمر استوكهولم عام المنظمات غير الحكومية بدور لا غني عنه في تحديد المخاطر وتقييم الآثار البيئية واتخاذ

$$
\text { الإجراءات لمعالجنها. }
$$

لذلك فإن التحرك نحو الاقتصاد الأخضر لديه القدرة علي تحقيق التتمية المستدامة

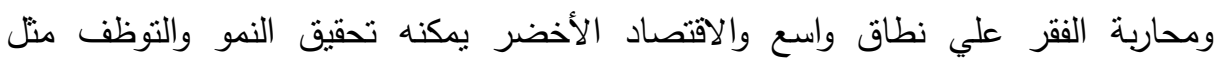
الاقتصاد البيئي ولكنه يحقق مالا يحققه الاقتصاد البيئي من اهتمام بالجوانب البيئية 


\section{إجراعاهي الصواسه}

$$
\text { أدوات البحث: }
$$

استمارة الاستبيان: مجموعة من أسئلة توجه إلي الأفراد من أجل الحصول علي المعلومات حول موضوع أو مشكلة أو موقف ويتم تتفيذ الاستمارة عن طريق المقابلة الثخصية.

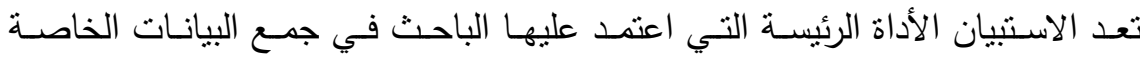
بالدراسة، لأنها من أنسب الأدوات لجمع أكبر قدر من البيانات من أفراد العينة.

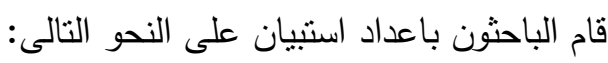
- هدف الاستيبان: دراسة دور الجمعيات فى التوجه نحو الاقتصاد الاخضر فى الشركات

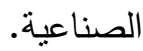
- محاور الاستبيان: فى محافظة القليوبية والقاهرة:

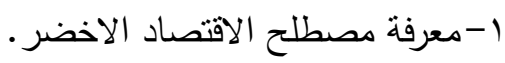

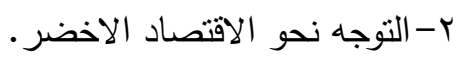

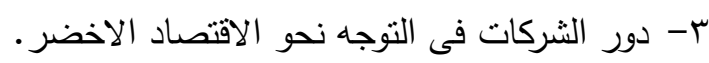

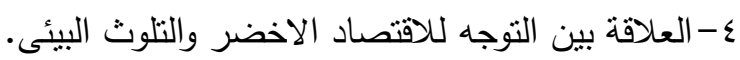
- عدد الاسئلة: شملت الاستمارة عدد • 9 من الاسئلة.

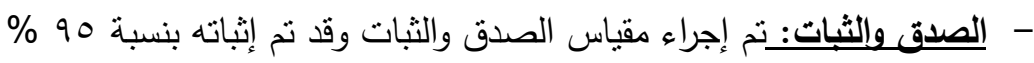

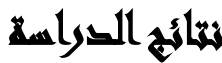

شملت الاراسة سبعة فصول كانت كما يلي: من خلال الدراسة الميدانية اتضح أن الدراسة قد حققت الفروض والأهداف حيث أن نتائج الدراسة الميدانية خلصت إنى إلى الآتي:

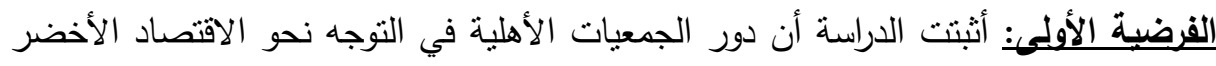

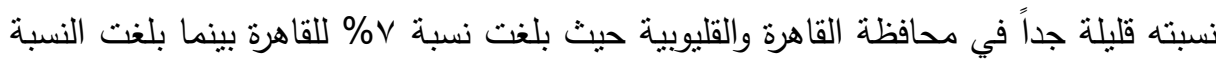


٪\% للقليوبية وهذا يعكس عدم اهتمام الجمعيات الأهلية بالتحول نحو الاقتصاد الأخضر واهتمامها بالنواحي الاجتماعية فقط الإعانات ومساعدة الفقراء.

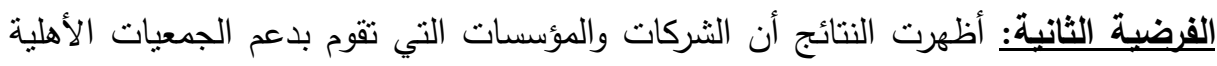
في مجال التحول إلى الاقتصاد الأخضر نسبتها قليلة جداً وهذا يعكس الفكر الذي يسبطر

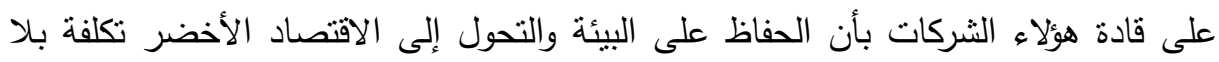
عائد ولذا يجب على الإعلام والدولة أن تعمل جاهدة لتغيير هذا الفكر للحفاظ على التى البيئة

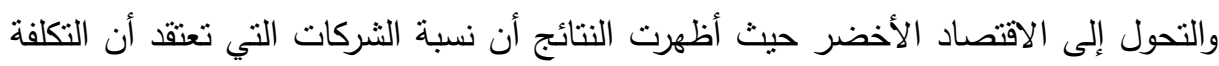
في القضاء على التلوث والتحول للاقتصاد الأخضر غير موافقين عليها كانت النسبة في

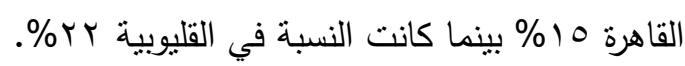
الفرضبة الثالثة: أن عدد الجمعيات الأهلية التي تعمل في مجال الاقتصاد الأخضر قليلة

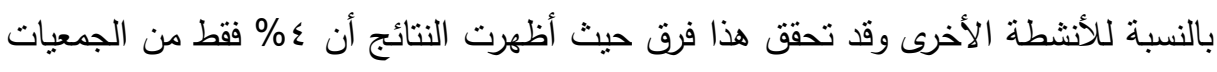

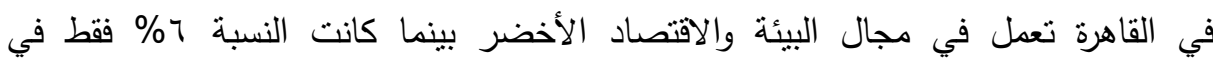
القليوبية. الفرضية الرايعة: انحصار دور الدولة وضعف الدعم للجمعيات الأهلية العاملة في مجال

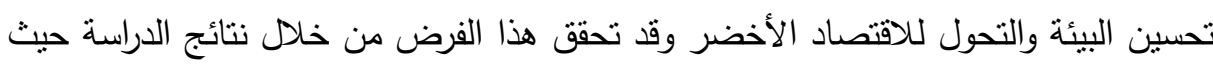

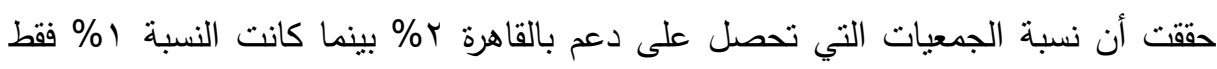
بمحافظة القليوبية وهذا يعكس انحصار دور الدولة في الاهتمام بالتتمية المستدامة وحماية البيئة.

الفرضية الخامسة: فنشل عدم قيام الجمعيات الأهلية بدورها المنوط به في مجال حماية البيئة والتحول للاقتصاد الأخضر بسبب ضعف التمويل وقد تحقق هذا الفرض حيث أظهرت النتائج

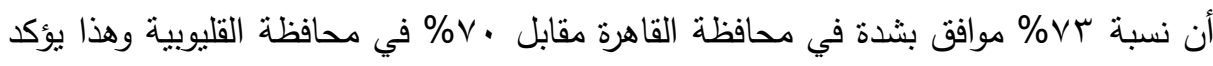

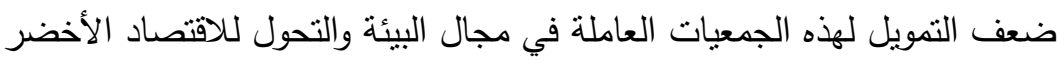




$$
\text { كما أظهرت الدراسة بعض النتائج التي تستوجب الاهتمام منها: }
$$

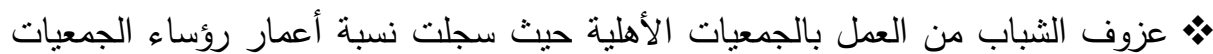

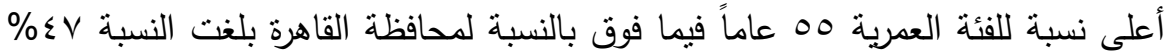
بينما بلغت في القليوبية بr\% وهذا يعكس عزوف الثباب عن العمل الأهلي لانشغاله بتكوين مستقبله في ظل الظروف الاقتصادية الحالية. • أكدت النتائج أيضاً أن النسبة للحالة العلمية لرؤساء ومجالس إدارات الجمعيات أن أقل نسبة كانت للحاصلين على الدكتوراه ع\% في القاهرة مقابل ب\% للقليوبية وهذا يعكس عدم تفرغهم وانشغالهم في أبحاثهم ودراستهم.

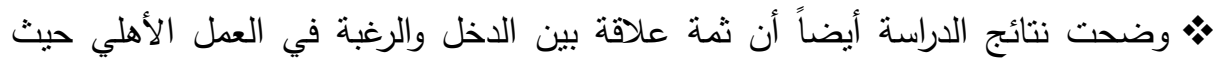

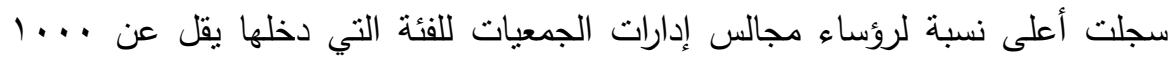
شهرياً r\% في القاهرة مقابل ه\% في القليوبية وهذا يعكس أن العمل الأهلي والتطوعي يحتاج إلى دخل كبير للقائم به. • سجلت البيانات أيضاً أن أعلى نسبة لرؤساء مجال إدارات الجمعيات الأهلية للعاملين في مجال التجارة rr\% في القاهرة مقابل ابـ\% في محافظة القليوبية.

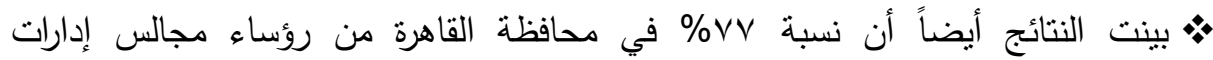

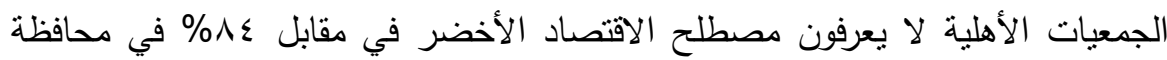
القليوبية. •ـ أظهرت النتائج أيضاً نسبة ارتفاع رغبة رؤساء مجالس إدارات الجمعيات الأهلية في

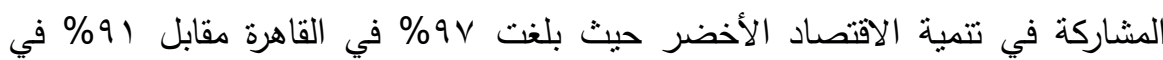
القليوبية. • كما أن نسبة مشاركة الجمعيات في أبحاث ومؤتمرات خاصة بالاقتصاد الأخضر متدنية

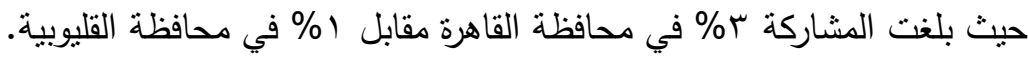

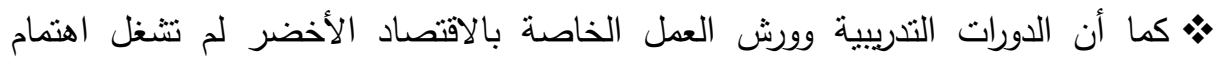
الجمعيات الأهلية حيث بلغت النسبة r\% في القاهرة بينما صفر في القليوبية. 
• كما أظهرت الدراسة أن نسبة الثركات الغير ملتزمة بالاثتراطات البيئية عالية جداً 99\% بالقاهرة مقابل \9\% في القليوبية وهذا يعكس مدى حاجاتتا إلى الاهتمام بالقضاء على بلى التلوث والحفاظ على البيئة. •• كما ظهرت النتائج أيضاً أن توافر عناصر الأمن والسلامة المهنية نسبته بـ\% في القاهرة مقابل سr\% في القليوبية. • اتضح من النتائج أيضاً أن الفلسفة الإدارية للشركات تجاه المساهمة ودعم الانتقال

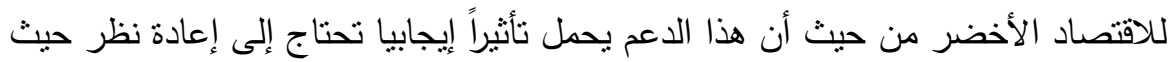
أن سr\% غير موافق على هذا في محافظة القاهرة بينما • ب\% في محافظة القليوبية وهذه النسبة كبيرة لعدم الموافقة. •• أظهرت النتائج أن مفهوم نجاح الشركة في الأجل الطويل يعتمد على مساهنها في بناء

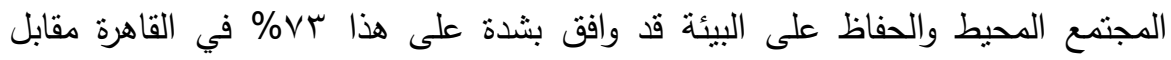

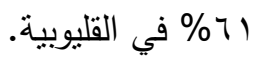

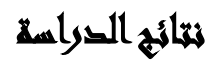

أولاً: حسب المعرفة بالاقتصاد الأخضر جدول(1): التوزيع النسبي للعينة حسب المعرفة بالاقتصاد الأخضر

\begin{tabular}{|c|c|c|c|c|}
\hline \multicolumn{2}{|c|}{ القليوبية } & \multicolumn{2}{|c|}{ القاهرة } & \multirow[b]{2}{*}{ البيان } \\
\hline النسبة & العدد & النسبة & العدد & \\
\hline$\% 17$ & 17 & \%rr & Tr & يعرف \\
\hline$\% \wedge \varepsilon$ & $\Lambda \varepsilon$ & $\% \vee V$ & $V V$ & لا يعرف \\
\hline$\% 1 \ldots$ & $1 \ldots$ & $\% 1 \ldots$ & $1 \ldots$ & المجموع \\
\hline
\end{tabular}

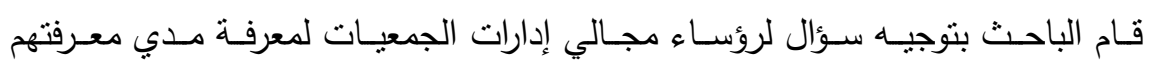
بالاقتصاد الأخضر وجدول (1) بين انخفاض نسبة المعرفة بالاقتصاد الأخضر لدي رؤساء مؤساء

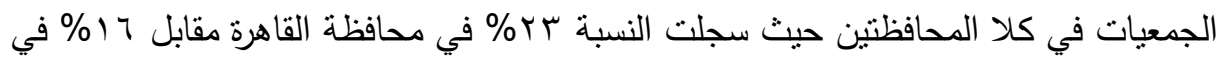
محافظة القليوبية وهذا انعكاس لأن مفهوم الاقتصاد الأخضر لم ينتشر بعد بالثكل الكافي 
ثانياً :التوزيع النسبي للعينة حسب طبيعة عمل الجمعية بمجال الآتصاد الأخضر.

جدول(ץ): التوزيع النسبي للعينة حسب طبيعة عمل الجمعية.

\begin{tabular}{|c|c|c|c|c|}
\hline \multicolumn{2}{|c|}{ القليويية } & \multicolumn{2}{|c|}{ القاهرة } & \multirow{2}{*}{ الخاصية } \\
\hline النسبـة & العدد & النسبـة & العدد & \\
\hline$\%$ \% & $\varepsilon$ & $\% \mathrm{~V}$ & V & يعمل \\
\hline$\% 97$ & 97 & $\% 94$ & $9 \pi$ & لا تعمل \\
\hline$\% 1 \ldots$ & $\ldots$ & $\% 1 \ldots$ & $\ldots$ & الإجمالى \\
\hline
\end{tabular}

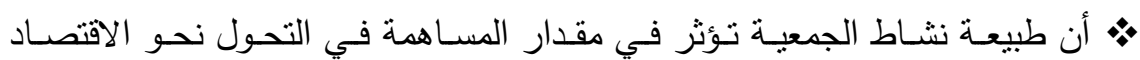

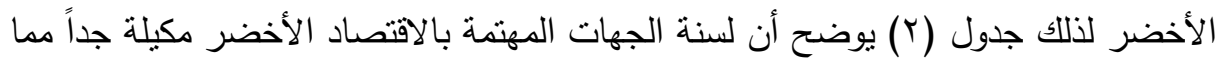

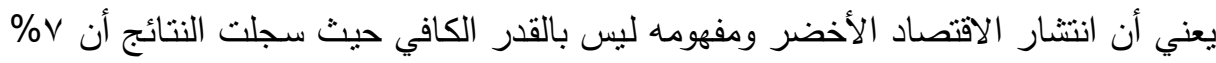

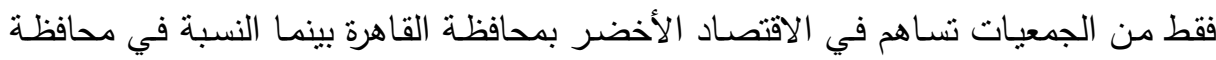
القليوبية ع \%

ثالثاً: التوزيع النسبي للعينة طبقاً لرغبة الجمعية في المشاركة في تتمية الاقتصاد الأخضر

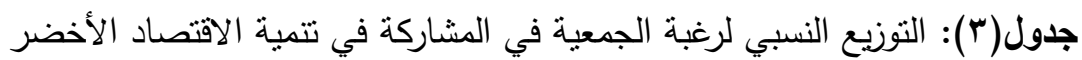

\begin{tabular}{|c|c|c|c|c|}
\hline \multicolumn{2}{|c|}{ القليويبة } & \multicolumn{2}{|c|}{ القاهرة } & \multirow{2}{*}{ البيان } \\
\hline النسبة & العدد - العد & النسبة & العدد - العد & \\
\hline$\% 91$ & 91 & $\%$ \% V & $9 \vee$ & لديها الرغبة \\
\hline$\% 9$ & 9 & $\% r$ & $\Gamma$ & لبس لديها الرغبة \\
\hline$\% 1 \ldots$ & $1 \ldots$ & $\% 1 \ldots$ & $1 \cdots$ & الإجمالي \\
\hline
\end{tabular}

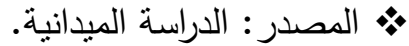

•ـ أظهرت النتائج من خـلال مستح العينة أن نسبة رغبـة الجمعيات في المساهمة في

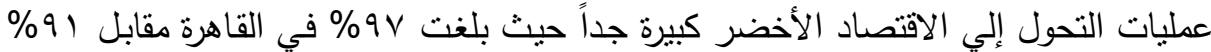
بالقليوبية وهذا يعكس زيادة الوعي بالعينة خلال العقود الأخيرة. 
رابعاً: التوزيع النسبي للعينة حسب مشاركة الجمعية في عمل انتاجي:

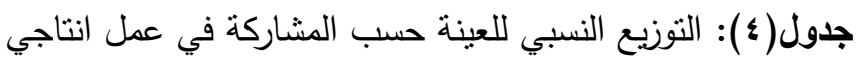

\begin{tabular}{|c|c|c|c|c|}
\hline \multicolumn{2}{|c|}{ القلتيونية } & \multicolumn{2}{|c|}{ القاهرة } & \multirow{2}{*}{ البيان } \\
\hline التسبة & العدد & النسبة & العدد & \\
\hline \% & r & $\% 1 \mathrm{~V}$ & $1 \mathrm{~V}$ & المشاركة \\
\hline$\% \vee V$ & $V V$ & $\%$ & NT & عدم المشاركة \\
\hline$\% 1 .$. & $1 \ldots$ & $\% 1 \ldots$ & $1 \cdots$ & الإجمالى \\
\hline
\end{tabular}

المصدر: الدراسة الميدانية

تضـح من جدول (ع) أن نسبة المشـاركة للجمعيـة في عمل انتـاجي بمحافظـة القاهرة

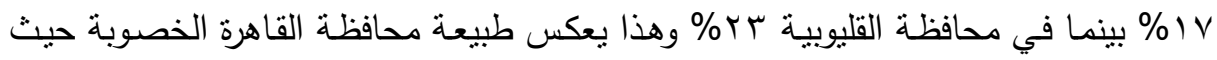
يكثر عمل الجمعيات في مشروعات انتاجية بالريف نظراً لعدم وجود فرص عمل.

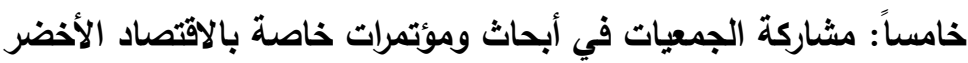

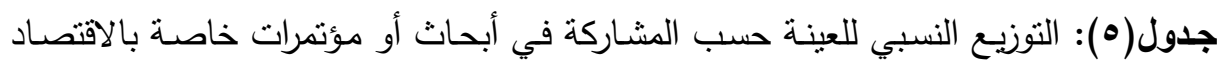

\begin{tabular}{|c|c|c|c|c|}
\hline & & & & الاخض \\
\hline \multicolumn{2}{|c|}{ القلّيويية } & \multicolumn{2}{|c|}{ القاهرة } & \multirow{2}{*}{ المشاركة } \\
\hline النسبـة & العدد & النسيـة & العدد & \\
\hline$\%$ \%1 & 1 & $\%$ \%r & $\bar{r}$ & المشاركة \\
\hline$\% 99$ & 99 & $\% 9 V$ & $9 V$ & عدم المشاركة \\
\hline$\% 1 \ldots$ & $1 \ldots$ & $\% 1 \ldots$ & $1 \ldots$ & الإجمالى \\
\hline
\end{tabular}

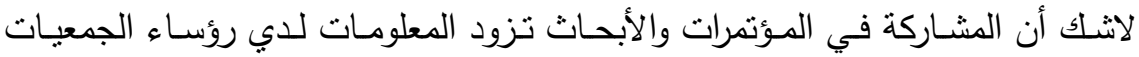

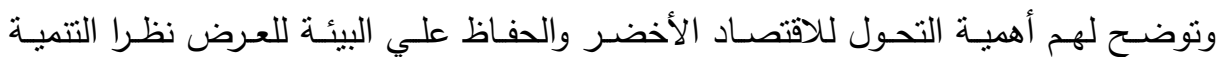
المستدامة. ونظراً لضآلة الإحصائيات في الأبحاث والمؤتمرات في مجال التحول إلي الاقتصاد

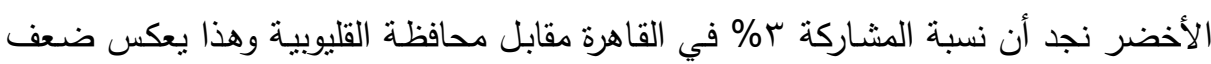
الاهتمام بالبيئة. 
سادساً: دعم الدولة للجمعية في مجال الاقتصاد الأخضر

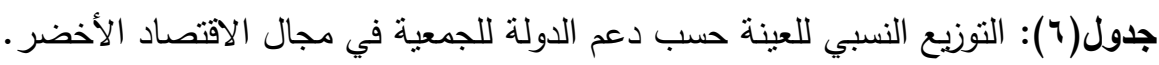

\begin{tabular}{|c|c|c|c|c|}
\hline \multicolumn{2}{|c|}{ القليوينية } & \multicolumn{2}{|c|}{ القاهرة } & \multirow{2}{*}{ البيان } \\
\hline النسبة & العدد & النسبةة & العدد & \\
\hline$\%$ & 1 & \%r & r & وجود دعم \\
\hline$\% 99$ & 99 & $\% 9 \wedge$ & 91 & لا بوحد دعم \\
\hline$\% 1 \ldots$ & $1 \ldots$ & $\% 1 .$. & $\cdots$ & الإجمالي \\
\hline
\end{tabular}

المصدر: الدراسة الميدانية:

للاولة دور كبير في الحفاظ علي التتمية المستدامة ومستقبل الأجيال القادمة وحمايتهم من التلوث إلا أن الميزانيات المخصصة لذللك قليلة رغم أهمية الموضوع.

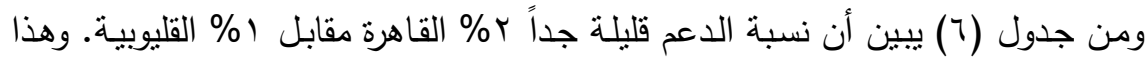
يتطلب زيادة الاعم من قبل الدولة الأفراد. سابعاً: التوزيع النسبي للعينة حسب المرور على الورش والثركات لمراجعة التلوث البيئي جدول(V): التوزيع النسبي للعينة حسب المرور علي الورش والثركات لمراجعة التلوث البيئي

\begin{tabular}{|c|c|c|c|c|}
\hline \multicolumn{2}{|c|}{ القليويبة } & \multicolumn{2}{|c|}{ القاهرة } & \multirow{2}{*}{ البيان } \\
\hline النسبة & العدد & النسبة & العدد & \\
\hline \%) & 1 & $\%$ \%r & $\overline{c r}$ & تعدم بالمرور \\
\hline$\% 99$ & 99 & $\% 91$ & 91 & لا تعدم بالمرور \\
\hline$\% 1 \ldots$ & $1 \ldots$ & $\% 1 \ldots$ & $1 \ldots$ & الإجمالي \\
\hline
\end{tabular}

المصدر: الدراسة الميدانية

جدول (V) يبين نسبة الجمعيات التي تقدم بـالمرور علي الورش والثـركات لمراجعة

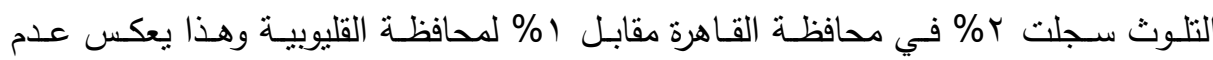
الاهنمام بالنشاط البيئي لدي الجمعيات مما يتطلب زيادة قيام الجمعيات الأهلية بالمساهمة في

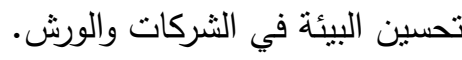


ثامناً: قيام الجمعية بمصر للشركات والورش الملوثة للبيئة. جلول(^): التوزيع النسبي للعينة حسب قيام الجمعية بحصر الثركات والورش الملوثة للبيئة بالمنطقة

\begin{tabular}{|c|c|c|c|c|}
\hline \multicolumn{2}{|c|}{ القليوينية } & \multicolumn{2}{|c|}{ القاهرة } & \multirow{2}{*}{ البيان } \\
\hline النسبة & العدد & التسبة & العدد & \\
\hline$\% r$ & r & $\%$ & $r$ & تم الحصر \\
\hline$\% 9 \wedge$ & 91 & $\% 9 V$ & $9 V$ & لم يتم الحصر \\
\hline$\% 1 .$. & $1 \ldots$ & $\% 1 \ldots$ & $1 \ldots$ & الإجمالى \\
\hline
\end{tabular}

المصدر: الدراسة الميدانية

أظهرت النتائج من جدول (^) أن نسبة قيام الجمعيات الأهلية بعمل حصر الثركات والورش الملوثة للبيئة يلقي r\% في القاهرة مقابل r\% لمحافظة القليوبية وهذا يبين عدم وجود

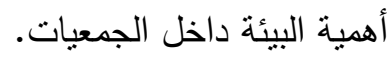
تاسعاً: التمويل الاجتماعي للاقتصاد الأخضر جدول (9) التوزيع النسبي للعينة حسب التمويل الاجنماعي لدعم الاقتصاد الأخضر الاحصر

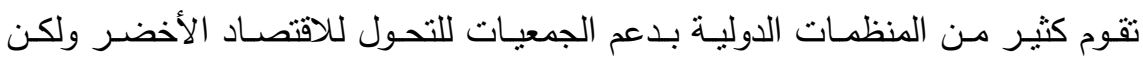
إيضاح أكدت ضعف التمويل الاجتماعي في التحول للاقتصاد الأخضر مقارناً بباقي الأنشطة الأخرى الحقوق الإنسان وغيرها من الأنشطة الأخري الحقوق الإنسان وغيرها من الأنشطة

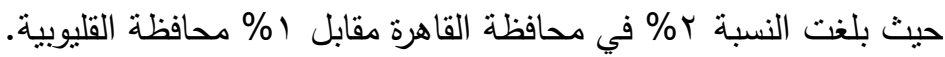
عاشراً: قرار عناصر الأمن والسلامة المهنية جدول( • 1): التوزيع النسبي للعينة حسب نوافر عناصر الأمن والسلامة المهنية بالمنطقة.

\begin{tabular}{|c|c|c|c|c|}
\hline \multicolumn{2}{|c|}{ القليويسة } & \multicolumn{2}{|c|}{ القاهرة } & \multirow{2}{*}{ البيان } \\
\hline النسبةة & العدد & النسبةة & العدد & \\
\hline \% & r & \% \% & קו & متوفر \\
\hline$\% 7 \mathrm{~V}$ & $7 V$ & $\% 7 \varepsilon$ & $7 \varepsilon$ & غير متوفر \\
\hline$\% 1 \ldots$ & $1 \ldots$ & $\% 1 \ldots$ & $1 \ldots$ & الإجمالى \\
\hline
\end{tabular}

المصدر : الدراسة الميدانية 
جدول (• () يبين التوزيـع النسبي للعينـة حسب توافر عناصـر الدعم والسـلام المهنيـة

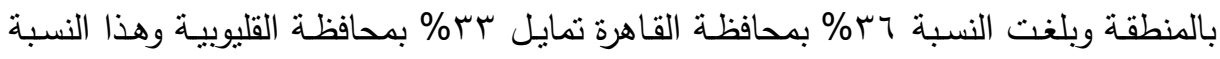

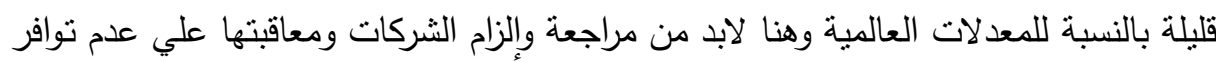

وسائل الأمن والسلامة المهنية.

\section{اتجاه الشركات نحو الاقتصاد الأخضر بمحافظة القاهرة والقليوبية:}

للشركات دور كبير في المساهمة في تحسين البيئة والتحول للاقتصاد الأخضر بالمناطق الموجود إليها وهي هذه الدراسة من خلال المسح الميداني نم الوصول إلي النتائج الآتية:

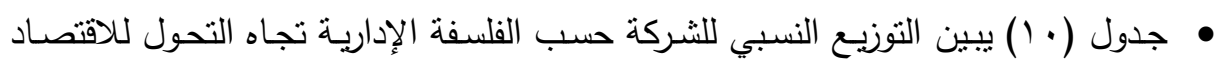
الأخضر واتضح من الجدول (• () أن حرص الثركات علي المجتمع يؤثر تأثيراً إيجابياً

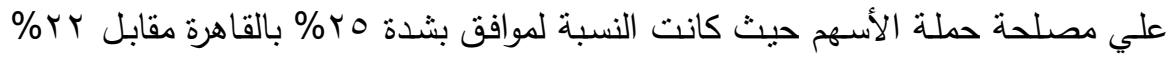

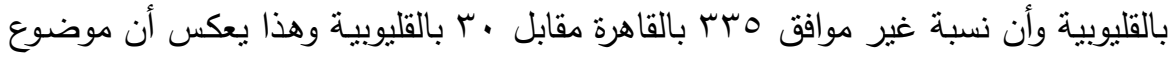

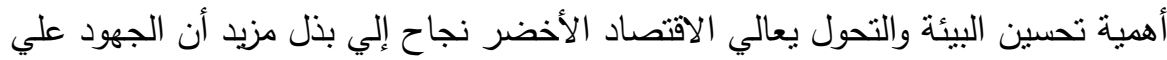

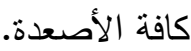
• كما حقق فرض أن نجاح الثركة في الأجل الطويل يعتمد علي قدرتها علي فهم أنها فرد

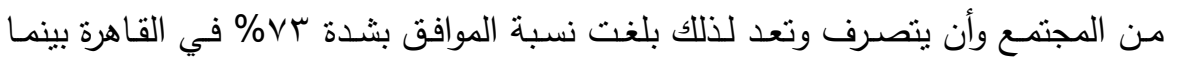

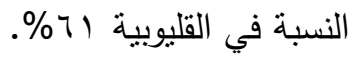
• أن الثركة في مساهمتها للقضاء علي النلوث تؤدي إلي ربح للشركة كانت النسبة لموافق

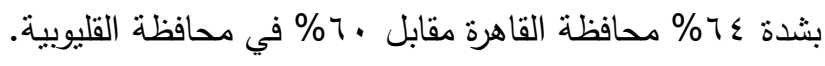
• الفلسفة الإدارية تجاه التحول للاقتصاد الأخضر للشركات بمحافظة القاهرة القليوبية. 
حادى عشر : الفلسفة الإدارية للشركات تجاه المساهمة في التحول للاقتصاد الأخضر

\begin{tabular}{|c|c|c|c|c|c|c|}
\hline \multicolumn{3}{|c|}{ القليوبية } & \multicolumn{3}{|c|}{ القاهرة } & \multirow[b]{2}{*}{ الغناصر } \\
\hline 产, & 高 & 骨 & 等, & 高 & 骨 & \\
\hline$r$. & «A & rY & rT & $\varepsilon r$ & ro & علي مصلحة حملة الأسهر الحرك الحريصة علي المجتمع يؤثر تأثيراً إيجابياً \\
\hline Ir & $\varepsilon r$ & 04 & 1. & $r \varepsilon$ & 74 & الثركات الإنتاج الفعال للسلع والخدمات هو مـا يطلبه المجتمع من \\
\hline $1 \varepsilon$ & ro & 11 & $1 \varepsilon$ & ir & $V T$ & 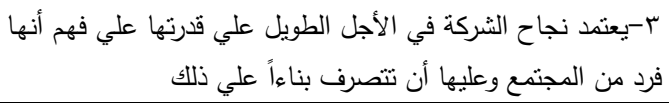 \\
\hline 11 & rT & זיד & 10 & rY & Tז & 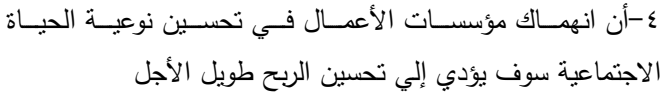 \\
\hline 9 & rq & $\pi$ & 9 & $r \varepsilon$ & TV & 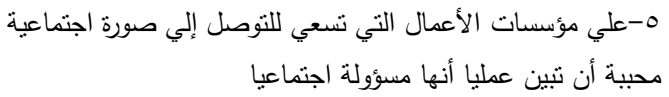 \\
\hline$i r$ & YV & 7. & 11 & ro & $1 \varepsilon$ & بطريقة تؤدي إلي ربح الثركة الاجتماعية كالسيطرة علي التلوث أحياناً \\
\hline
\end{tabular}

من خلال نتائج الاراسة فلخص إلى بعض التوصيات كما يلي:

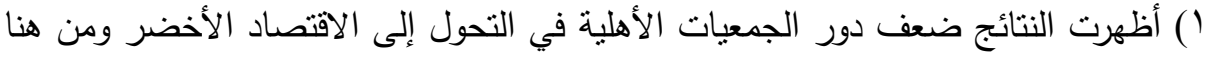

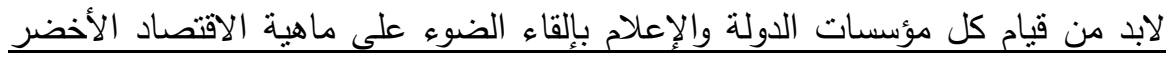

$$
\text { وفوائده وحق الأجيال القادمة في التنمية المستدامة. }
$$

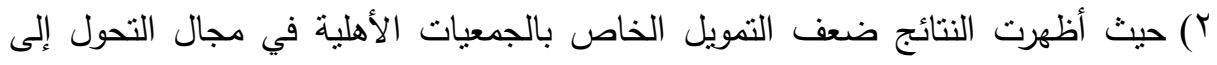
الاقتصاد الأخضر توصى بعمل برامج توعية وتشريعات تلزم الثركات والورش والمؤسسات

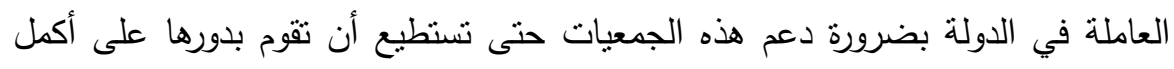


r) أظهرت النتائج أيضاً قلة نسبة الجمعيات الأهلية العاملة في مجال البيئة والتحول إلى الى الاقتصاد الأخضر ومن هنا لابد للاولة من تشجيع وتسهيل قيام منل هذه الجمعيات لأداء دورها ولأهمية دورها أيضاً للوصول للتنمية المستدامة. §) برنامج عمل الاقتصاد الأخضر هو برنامج واسع النطاق يُعني بجميع النواحي لورهي

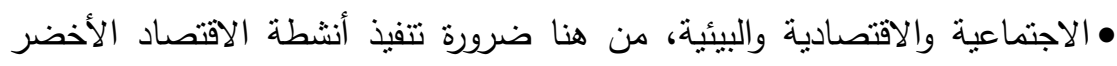
حسب الأولوية في القطاعات الرئيسية التي تؤثز على المجتمعات العربية على المدى القصبر.وخاصة على الثباب والنساء والفقراء والفئات الضعيفة.

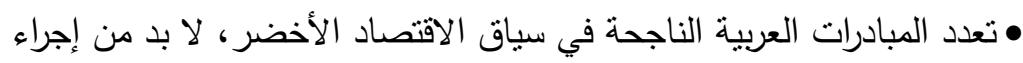

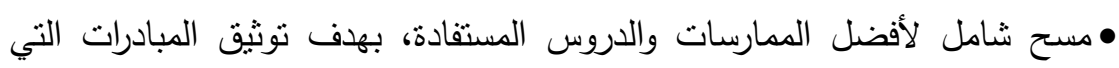
نجحت في بعض البلدان العربية في مجال الاقتصاد الأخضر والاستفادة منها في بلدان أخرى.

0) تشجيع فرص العمل الخضراء في المنطقة العربية في مناخ الانتقال إلى الديمقراطية • الذي نتهده عدة بلدان عربية، ولذلك لا بد من تلبية الحاجة إلى التدريب وتتمية

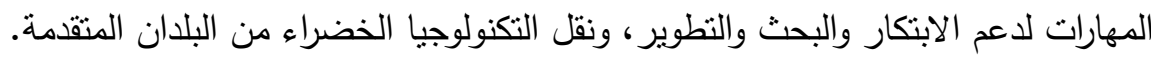

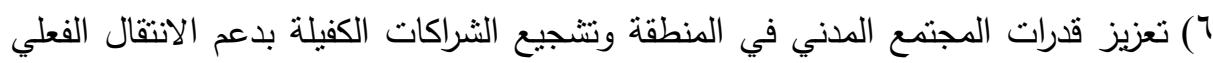

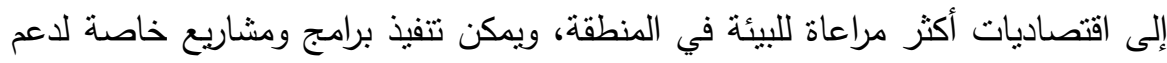
الاستثمار الأخضر في المؤسسات الصغيرة والمتوسطة، والاستفادة من تجارب الاستثمار الأخضر الذي تقوم به هذه الثركات، لا سيما في توليد فرص العمل ومصادر الاخل الخضراء في إطار التحول إلى الاقتصاد الأخضر.

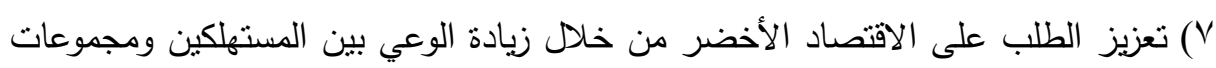

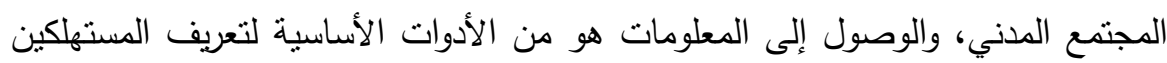
بمفاعيل ما يتخذونه من قرارات على صعيد الاستهلاك، ولتحقيق ذلك، لا بد من بناء شراكات مع المستهلكين ومنظمات المجتمع المحلي ووسائل الإعلام بهدف التوعية بمفاهيم الاقتصاد الأخضر ومبادئه. 


\section{المرالئي}

أبو طير نبيل، المحروقات والتتمية المستدامة ومدى أهمية المراهنة على الطاقات البيئية،

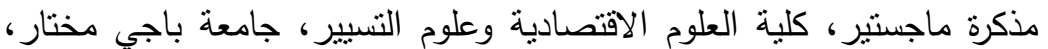

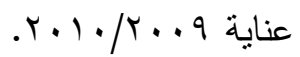

أحمد زايد، تصميم البحث الاجتماعي (أسس منهجية وتطبيقات عملية)، القاهرة، مكتبة الأنجلو

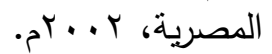

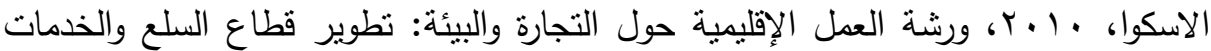

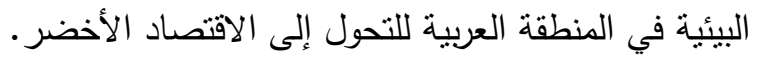

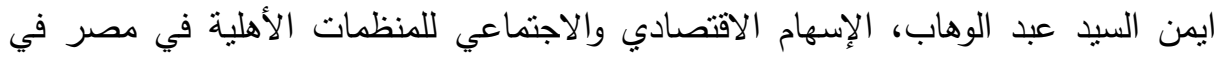

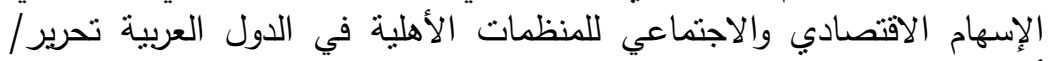
أماني قنديل للشبكة العربية للمنظمات الأهلية، 1999 الإنيات برنامج الأمم المتحدة الإنمائي، 9 . . r، تقرير التتمية الإنسانية العربية.

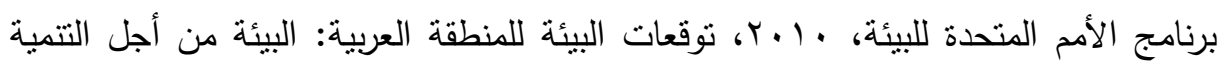
ورفاهية الإنسان.

برنامج الأمم المتحددة الإنمائي، 9 . . ب، تقرير التتمية الإنسانية العربية.

Ibrahim El-Bayoumi Ghanem (2203). The Culture of Volunteerism in the Contemporary Arab Society: Components, Problematic and the Need for Vitalization. Nahda, Fifteenth Issue, April 2003.

Vagiad, Wade M. (2006). Likert-type scale response anchors. Clemson International Institute for Tourism \& Research Development, Department of Parks, Recereation and Tousrism Management, Clemson University.

International Energy Agency (IEA), 2010, CO2 Emissions from fuel Combustion 2010- Highlights.

Management Guru, Potential economic benefits from uprising in Egypt, available at http://themanagmentgurublogsport.com/2011/03/potentialeconoic-benegits-from.html.

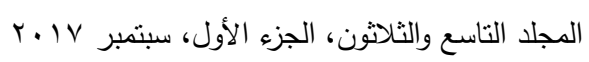


Mellor, Warren L. (2001). Reason for Hope: The Support of NGOs to Education for All. Unesco, Graphoprint.

\title{
A SUGGESTED STRATEGY TO DIRECT INVESTMENTS TOWARDS GREEN ECONOMY A CASE STUDY ON THE CIVIL ASSOCIATIONS
}

\author{
Sobh, M. M. ${ }^{(1)}$; Awad, M. I. ${ }^{(2)}$; Abdel Baset, W. F. ${ }^{(1)}$ \\ and Hafez, H. A
}

1) The Faculty of Commerce, Ain Shams University 2) Institute of Environmental Studies \& Research, Ain Shams University

\begin{abstract}
The study handled the way of directing the green economy as well as the role of civil associations in getting interested in the green economy as the economy in general needs to preserve the environment \& sustainable development to keep the rights of the coming generations.

As for the term; the green economy- it means- a system that guarteentees the presence of economic \& service activities in a way that betters the interest of human beings; \& never let them face any environmental dangers or rare cases, the study included seven chapters the first one the introduction -the problem of the study- the importance of the study \& its hypothesis- then the scientific methodology used in this study \& the previous studies-the second chapter discussed the meaning of the green economy \& the third chapter how to move towards the green economy the forth one the suggested priorities to lay a strategy regarding this kind of economy the forth one handled the priorities of the green economy \& the fifth one the role of civil society in preserving the environment the sixth chapter handled the field study that included the Cairo \& Qalioubia governorates ; the role of civil

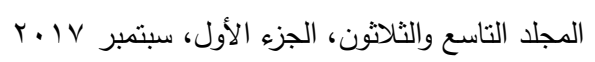


societies towards transferring to the green economy as well as the role of companies in supporting the green economy

The study reached the fact that there is a lack in the number of societies that are working in the transfer towards green economy \& the role of companies in supporting the green economy did not reach yet the good percentage that helps in the preservation of the environment - also the role of the state is limited and the support given to civil entities to perform their job is not sufficient

The lack of safety \& good climate in Cairo \& Qalioubia governorates. The results of the study have also shown that the media must exert more efforts to let us know of the importance of the green economy; the state must support the civil societies especially those working in the field of preservation of the environment; the companies must as well perform their role in preserving the environment $\&$ getting directed to the green economy also the researchers must work in more than one direction towards the green economy 